\title{
O ENSINO MÉDIO POLITÉCNICO: A PESQUISA ESCOLAR
}

\author{
POLYTECHNIC HIGH SCHOOL: SCHOOL RESEARCH
}

\author{
Cláudia Schvingel Klein Bühring \\ Doutora em Ensino. \\ Universidade do Vale do Taquari - UNIVATES. \\ Lajeado, RS - Brasil. \\ cschvingel@universo.univates.br \\ Ieda Maria Giongo \\ Doutora em Educação \\ Universidade do Vale do Rio dos Sinos - UNISINOS. \\ São Leopoldo, RS - Brasil. \\ igiongo@univates.br \\ Angélica Vier Munhoz \\ Doutora em Educação \\ Universidade Federal do Rio Grande do Sul - UFRGS. \\ Porto Alegre, RS - Brasil. \\ angelicavmunhoz@gmail.com
}

\begin{abstract}
Resumo: O objetivo do presente texto é investigar como o ensino pela pesquisa consistiu em um Princípio Pedagógico da Proposta do Ensino Médio Politécnico no Estado do Rio Grande do Sul. Oriunda de uma dissertação de Mestrado em Ensino, a investigação tem como aportes teóricos algumas ferramentas foucaultianas, em especial as noções de enunciado e discurso e reflexões acerca da pesquisa escolar, a partir de autores, como Corazza (2013). O material para a análise foi gerado por meio de entrevistas semiestruturadas, com três docentes que atuavam em cargos administrativos à época da implantação da Proposta, e da técnica de grupo focal com nove docentes de uma escola de Ensino Médio do interior do Vale do Taquari/RS. Aliados a isso, realizaram-se estudos dos documentos base da Proposta da Legislação vigente e pesquisa em dois jornais de circulação. Os resultados mostram que a pesquisa tem sido evidenciada somente na disciplina de Seminário Integrado, mas, segundo a Proposta, as demais também deveriam gerar investigações numa perspectiva interdisciplinar. Ainda, o como "fazer pesquisa" foi sendo constituído entre os professores por meio de um conjunto de formulações realizadas ao longo da história da educação. Por fim, o desafio está na criação e na inovação de uma pesquisa-docência que provoque rupturas nas formas de ensinar e de aprender.
\end{abstract}

Palavras-chave: Ensino médio politécnico. Pesquisa escolar. Seminário integrado.

Abstract: The objective of this paper is to investigate how teaching the research consisted in Teaching Principle of Proposal of the Polytechnic School in the state of Rio Grande do Sul. The work was originated from a research in Master in Teaching program and has as theoretical framework some foucauldian tools, especially the notions of enunciation and speech and discourse. The material for analysis was generated through semi-structured interviews with three teachers who worked in administrative positions at the time of implementation of the Proposal, and the focus group technique with nine teachers from a high school in Vale do Taquari, Rio grande do Sul State. There have also been studies of the basis of the Proposal's documents and research in two newspapers. The results showed that the research has been observed only in the Integrated Seminar discipline to the detriment of others, which according to the Proposal, should also generate investigations from an interdisciplinary perspective.

Keywords: Polytechnic high school. School research. Integrated seminar.

Para citar - (ABNT NBR 6023:2018)

BÜHRING, Cláudia Schvingel Klein; GIONGO, Ieda Maria; MUNHOZ, Angélica Vier. O ensino médio politécnico: a pesquisa escolar. Eccos - Revista Científica, São Paulo, n. 56, p. 1-14, e8776, jan./mar. 2021. Disponível em: https://doi.org/10.5585/eccos.n56.8776. 


\section{Introdução}

Em 2011, a Secretaria de Educação do Estado do Rio Grande do Sul divulgou à sociedade gaúcha o denominado Ensino Médio Politécnico. Por conta disso, apresentou dois documentos-base às escolas estaduais: a Proposta Pedagógica para o Ensino Médio Politécnico e Educação Profissional Integrada ao Ensino Médio, 2011-2014 e o Regimento Referência, 2012. A referida Proposta foi implementada nas escolas estaduais em 2012.

Essa organização, uma política pública do Governo do Estado -2011-2014-, propunha um trabalho coletivo efetivado na prática, integrando os diferentes atores que trabalhavam nas escolas, nas instituições responsáveis pela formação de professores e nos órgãos públicos. Como ponto de partida, estavam os processos de trabalho que superariam a lógica disciplinar e a superposição de conteúdos gerais e específicos para novas formas de seleção e organização dos conhecimentos, no diálogo entre a teoria e a prática (RIO GRANDE DO SUL, 2011-2014). Dessa forma, o currículo deveria "[...] resgatar o sentido da escola como espaço de desenvolvimento e aprendizagem, [...]” (RIO GRANDE DO SUL, 2011-2014, p. $15)$.

Em função disso, ao estudarmos os documentos-base, constatamos a presença de palavras e expressões revisitadas: projetos interdisciplinares, trabalho, protagonismo, politecnia, pesquisa, áreas do conhecimento, construção do conhecimento, entre outras. O que mais chamou a nossa atenção e nos mobilizou à investigação foi, precisamente, a palavra “pesquisa”. Esta, nos referidos documentos, endossava a relação do professor do Ensino Médio Politécnico e os enunciados em torno dela.

A pesquisa escolar, conforme a Proposta, era compreendida como princípio pedagógico que "[...] implica na identificação de uma dúvida ou problema, na interpretação e elaboração dessas informações e na organização e relato sobre o conhecimento adquirido" (UNESCO apud RIO GRANDE DO SUL, 2011-2014, p. 21). Além de ser proferida como princípio pedagógico da Proposta, a pesquisa era apontada como central na disciplina de Seminário Integrado (SI). Esta, acrescentada ao currículo das áreas do conhecimento do Ensino Médio Politécnico, era trabalhada por meio de projetos interdisciplinares (Rio Grande do Sul 2011-2014 e 2012).

Em razão disso, fomos levadas a problematizar questões vinculadas à pesquisa escolar quando evidenciada "[...] como princípio pedagógico [...], [...] orientada e motivada pelos professores [...]" (RIO GRANDE DO SUL, 2011-2014, p. 21). Além disso, perguntamo-nos como o ensino pela pesquisa se constituiu enquanto princípio pedagógico da Proposta do 
Ensino Médio Politécnico.

A investigação acerca da Proposta do Ensino Médio Politécnico se originou de estudos de uma dissertação de Mestrado. A pesquisa, de cunho qualitativo, fez uso da entrevista semiestruturada com três profissionais ligados ao Ensino Médio que ocupavam cargos administrativos, em 2014, época do estudo, e grupo focal com nove professores das diferentes áreas do conhecimento de uma Escola de Ensino Médio Politécnico do Vale do Taquari/RS.

Nessa perspectiva, compreendemos que a entrevista semiestruturada é uma das metodologias mais utilizadas na investigação de um tema ou problema. Por isso, reportamonos a Costa (2005), que teoriza a arte de perguntar: "Tais perguntas emergem de uma certa insatisfação, de uma certa instabilidade, de uma certa dúvida, de uma certa desconfiança, de uma certa insegurança aventurosa" (COSTA, 2005, p. 200). Ao utilizarmos a técnica de grupo focal, mencionamos Dal'Igna (2012, p. 204) quando esta diferencia a técnica de grupo focal das outras, como sendo

[...] potencial para produção de informações sobre tópicos específicos, a partir do diálogo entre participantes de um mesmo grupo. Este diálogo deve estimular tanto as ideias consensuais quanto as contrárias. Da mesma forma, a técnica de grupo focal, diferentemente de entrevistas (individuais ou coletivas), permite produzir um material empírico a partir do qual se pode analisar diálogos sobre determinados temas e não falas isoladas.

Além disso, estudamos os documentos da Proposta Pedagógica para o Ensino Médio Politécnico e Educação Profissional Integrada ao Ensino Médio (2011-2014); o Regimento Referência das Escolas de Ensino Médio Politécnico da Rede Estadual (2012); o Parecer CNE/CEB n ${ }^{\circ}$ 5/2011, que homologou as Diretrizes Curriculares Nacionais para o Ensino Médio e as Diretrizes Curriculares Nacionais Gerais da Educação Básica de 2013. Também analisamos reportagens expressas pela mídia em dois jornais de circulação no Vale do Taquari/RS e o diário de campo da pesquisadora.

Por questões de ética em pesquisa, nomeamos os nove professores participantes da técnica de grupo focal Professor A (PA); Professor B (PB); Professor C (PC); Professor D (PD); Professor E (PE); Professor F (PF); Professor G (PG); Professor H (PH); Professor I (PI). Quanto aos três profissionais participantes da entrevista semiestruturada, denominamolos Entrevistado 1 (E1); Entrevistado 2 (E2); Entrevistado 3 (E3). Todos os participantes assinaram o Termo de Consentimento Livre e Esclarecido. Cabe lembrar que a presente pesquisa contou com o apoio da FAPERGS/CAPES ${ }^{1}$ (Fundação de Amparo à Pesquisa do

\footnotetext{
${ }^{1}$ Maiores informações em: http://www.fapergs.rs.gov.br/
} 
Estado do Rio Grande do Sul).

A análise do material de pesquisa está alicerçada em algumas ferramentas do pensamento de Foucault (2008, 2011), em especial suas noções de enunciado e discurso. Ademais, em nossas reflexões acerca da pesquisa escolar, apoiamo-nos em autores, como Corazza (2013).

\section{Desenvolvimento}

A análise dos documentos relativos à Proposta do Ensino Médio Politécnico e dos enunciados em torno dela demanda um olhar atento que foge da fácil interpretação do que está escrito, exigindo uma investigação cuidadosa. Neste trabalho, os enunciados sobre o Ensino Médio Politécnico não foram examinados unicamente pelo significado das palavras que os constituem, mas sim escrutinados, considerando-se que esses discursos estavam sendo ditos em detrimento de outros. Para que uma sequência de frases como a que está escrita nos documentos relativos à Proposta, nas reportagens, nos enunciados dos professores sobre o Ensino Médio Politécnico possa ser considerada e analisada como um discurso, é preciso que tenha "[...] existência material" (FOUCAULT, 2008, p. 113). O autor reforça a ideia afirmando que "[...] o enunciado precisa ter uma substância, um suporte, um lugar e uma data" (FOUCAULT, 2008, p. 114).

Para Foucault (2008), não há nada sob o chão que pisamos, mas enunciados e relações que o próprio discurso põe em funcionamento. Ou seja, analisar o discurso acerca de um objeto e, aqui, a Proposta do Ensino Médio Politécnico, em especial a pesquisa escolar motivada e orientada pelos professores, era dar conta das relações históricas. As palavras expressas no grupo focal, nas entrevistas e nos documentos estudados também são construções, linguagens constituidoras de práticas. Foucault (2012, p. 53) afirma que

[...] a história há muito tempo não procura mais compreender os acontecimentos por
um jogo de causas e efeitos na unidade informe de um grande devir, vagamente
homogêneo ou rigidamente hierarquizado; [...] É para estabelecer as séries diversas,
entrecruzadas, divergentes muitas vezes, mas não autônomas, que permitem
circunscrever o lugar do acontecimento, as margens de sua contingência, as
condições de sua aparição.

Nas teorizações de Foucault (2012), aparece a íntima relação entre discurso, poder e saber. Para o autor, a questão está em percebermos de que modo o saber "[...] é aplicado em uma sociedade, como é valorizado, distribuído, repartido e de certo modo atribuído" (FOUCAULT, 2012, p. 17). O filósofo acrescenta que a história sempre nos mostra que o discurso não é simplesmente aquilo que traduz as lutas daqueles que dominam, mas algo pelo 
qual lutamos, o poder do qual queremos nos apoderar. Foucault se aproxima dos modos de vida dos gregos clássicos para compreender o que fizemos de nós mesmos e como produzimos determinadas verdades, discursos que passaram a nos constituir enquanto sujeitos.

Cada época produz os seus discursos que se constituem como regimes de verdade. Essa produção é controlada, selecionada, redistribuída e Foucault (2012, p. 8-9) expressa que tudo isso acontece "[...] por um certo número de procedimentos que tem por função conjugar seus poderes e perigos, dominar seu acontecimento aleatório, esquivar sua pesada e temível materialidade". Logo, que o que está em jogo em cada sociedade e tempo é “[...] senão o desejo e o poder do discurso" (FOUCAULT, 2012, p. 19). E o próprio discurso exerce seu controle e pode-se "[...] supor que há, muito regularmente nas sociedades, uma espécie de desnivelamento entre os discursos: os discursos que se dizem" (FOUCAULT, 2012, p. 21).

Assim sendo, o que pretendemos neste trabalho não é fazer uma análise linear do discurso e das continuidades presentes nos documentos, mas sim examinar a Proposta do Ensino Médio Politécnico quando trata da pesquisa escolar. Ou seja: Quais discursos constituem a Proposta como verdadeira? Quais são as verdades enunciadas em torno dela? Além disso, o estudo dos documentos da Proposta do Ensino Médio, que trata da pesquisa como prática a ser desenvolvida pelos professores nos ambientes escolares, fez com que pensássemos acerca "das formas" de produção de conhecimento nos espaços escolares?

De fato, a pesquisa evidenciou que o professor era o protagonista da proposta do Ensino Médio Politécnico e, nessa perspectiva, orientou e motivou o aluno a desenvolvê-la. Ademais, ele estudou os documentos e proporcionou, por meio destes, práticas pedagógicas diferenciadas e alicerçadas.

Essas leituras nos induziram ainda a pensar se, de fato, os docentes do Ensino Médio Politécnico estavam colocando em evidência e problematizando as suas práticas pedagógicas e como o movimento da pesquisa vinha se efetivando nas escolas estaduais de Ensino Médio Politécnico. Algumas reflexões de Kohan (2004) propõem a busca de outro professor, sugerindo o abandono do que era, abrindo espaço para ser outro. Por sua vez, Ohlweiler (2012) sugere "[...] pensarmos na relação entre o ensino e a pesquisa por meio de duas instâncias principais: o professor pesquisador e o aluno pesquisador" (OHLWEILER, 2012, p. 82).

Ao buscarmos seus escritos, destacamos uma instância principal de sua pesquisa e também da nossa: o professor pesquisador. Ainda para a autora, “[...] a interlocução que 
propomos entre ensino e pesquisa denota que a aprendizagem não está nem em um, nem no outro, está entre e por isso tem e traz elementos de ambos" (OHLWEILER, 2012, p. 84). Já para Corazza (2013, p. 94), “[...] todo professor é um pesquisador, possui um espírito pesquisador, entre em devires pesquisadores, enquanto educa [...]. Ensinar (fazendo pesquisa) e pesquisar (ensinando) consistem, dessa maneira, em criar soluções e, ao mesmo tempo, enigmas".

Nesse sentido, Corazza (2013) também evidencia que, por muito tempo, sustentou-se a ideia de que, de um lado, estariam os pouquíssimos intelectuais da educação e, de outro, a maioria, como se houvesse uma divisão em castas. A autora atesta que "[...] docência sem pesquisa não existe, nunca existiu, nem existirá" (2013, p. 93). A citada pesquisadora sustenta que a docência sempre foi pesquisa e vice-versa. Sua ideia está ancorada em três linhas transversais, que se encontram em movimento desde o século XX, quais sejam: “[...] uma linha de força mundial, uma nova linha de teorização nas ciências humanas e sociais e uma linha que atravessa os próprios educadores" (CORAZZA, 2013, p. 95).

O exercício de pensar a pesquisa, o professor e o ensino nos documentos da Proposta do Ensino Médio Politécnico para as escolas estaduais e o contexto educacional atual necessitam movimentar várias passagens e desmontagens. Conforme Corazza (2004),

[...] enquanto o sentido de pesquisar não transcende o movimento da própria pesquisa e a professora-pesquisadora não pesquisa fora do plano de consistência da pesquisa, nem fora de sua própria ação, de maneira que só a pesquisa lhe dá o sentido do seu pesquisar e ela não encontra jamais o sentido da pesquisa que faz (CORAZZA, 2004, p. 9-10).

Corazza (2004) também escreve que a pesquisa não é uma simples passagem do não saber para o saber de um determinado assunto ou conteúdo que está sendo pesquisado, mas muito mais: é pensar o modelo que temos incorporado sobre o fazer pesquisa, ou melhor, como estamos operando com ela. Munidos desses referenciais, apontamos, nas próximas seções, algumas discussões e considerações finais da investigação.

\section{Algumas discussões}

Ou na prática agora estas diferentes áreas vão ajudar estes projetos? Em que momento? Nas suas aulas? Eu não sei como no concreto todas as áreas entrariam nestes projetos de pesquisa? Como isto na prática seria? (Excerto extraído da técnica de grupo focal, PE).

O excerto acima, extraído de um dos encontros do grupo focal, foi central para que nos debruçássemos a estudar questões vinculadas ao Seminário integrado. Muitas 
problematizações acerca dessa temática foram geradas pelos docentes. Estes questionavam o modo como a pesquisa estava sendo desenvolvida e compreendida entre os professores das diversas áreas do conhecimento no tocante à disciplina de Seminário Integrado. Cabe destacar que o princípio pedagógico "pesquisa" e a disciplina "Seminário Integrado" (SI) suscitaram vários debates - favoráveis e contrários - na comunidade rio-grandense, expressos em alguns excertos:

\section{Quadro $1^{2}$ - Excertos A}

Seminário é matação (O INFORMATIVO, 20 ago. 2013, p.11).

Mais conteúdo, menos pesquisa (A HORA, 22 ago. 2013, p. 1).

[...] e a pesquisa possibilita essa interação, entre os sujeitos e onde todos aprendem, inclusive, os professores, [...] (Excerto extraído da entrevista semiestruturada, E3).

Fonte: Produções docentes (2014).

As enunciações do quadro revelam os diferentes entendimentos acerca da "pesquisa" e da disciplina "SI". Estas não eram compreendidas de forma dissociada, mas imbricadas num processo de ensinar e aprender. Ademais, é perceptível que ambas sofriam uma certa "negação", já que, por exemplo, de acordo com o Jornal O Informativo, "Seminário é uma matação". Essas questões nos levaram a perceber as relações teóricas que o grupo estabeleceu para o desenvolvimento da "pesquisa" na disciplina de "SI".

\section{Quadro 2 - Excertos B}

[...], acho que um dos motivos dos seminários é que a gente planeja muito, e as disciplinas a gente não senta e [não] planeja junto, [...] (Excerto extraído da técnica de grupo focal, PA).

[...] a pesquisa voltada ao seminário, e não como uma proposta de Ensino Médio Politécnico (Excerto extraído da técnica de grupo focal, PB).

[...] a pesquisa a gente traz para o seminário e não para as disciplinas (Excerto extraído da técnica de grupo focal, PB).

[...] o seminário integrado não é uma disciplina para um professor diferente dar aula, [...] (Excerto extraído da entrevista semiestruturada, E1).

Fonte: Produções docentes (2014).

De fato, ao serem questionados, em um dos encontros do grupo focal, se a "pesquisa" acontecia somente no "SI", os professores, de forma unânime, declararam que "sim". Quanto à pergunta "E na área do seu conhecimento?", um deles respondeu: "Não sei as outras

\footnotetext{
${ }^{2}$ Alguns materiais de pesquisa estão expressos em quadros para facilitar a compreensão.
} 
disciplinas, não interagiam com aquela pesquisa [...]" (Excerto extraído da técnica de grupo focal, PE).

Algumas enunciações do quadro também evidenciam que a pesquisa era trabalhada na disciplina de "SI" e não enquanto proposta, pois, segundo os professores, ela [a pesquisa] não envolvia as demais disciplinas. Outro fato que nos chamou a atenção foi quando um docente declarou que "assumiu a pesquisa, ou seja, a disciplina de "SI” para completar sua carga horária".

Seguindo Foucault (2008), não importa se uma emissão de enunciados, como os que foram expressos neste trabalho, esteja sendo feita pela primeira vez, o que conta é a sua regularidade e raridade. A sua repetição não ocorre em função de questões exteriores, mas da sua materialidade interna, que faz dessa repetição a força característica dos enunciados. Para compreendermos um enunciado, é necessário entendermos a modalidade da existência de um conjunto de signos que se torna repetível. Ele se exerce por intermédio de elementos significativos de frases e proposições, que coincidem com a descrição das formações discursivas. Portanto, um discurso é um conjunto de enunciados que pertence a campos diferentes, mas com regras de funcionamento comuns e que designa um conjunto de performances verbais.

Tais enunciados também podem ser visualizados na Figura 3, que contém a descrição do documento base da Proposta Pedagógica, que aponta a ampliação de horas na organização curricular, em especial da disciplina de "SI" para o Ensino Médio Politécnico:

\section{Quadro 3 - Excertos C}

O acréscimo de $600 \mathrm{~h}$ nas atuais $2400 \mathrm{~h}$, dividido nos três anos, se traduzirá por possibilidades de estágios ou aproveitamento de situações de emprego formal ou informal, desde que seu conteúdo passe a compor os projetos desenvolvidos nos seminários integrados e, com isso, venha a fazer parte do currículo do curso.

Fonte: Rio Grande do Sul (2011-2014, p. 22-23).

Ademais, a grade curricular dispõe de dois blocos de estudo: a Formação Geral e a Parte Diversificada. A primeira é compreendida como o núcleo comum desenvolvido por meio de um trabalho interdisciplinar com as áreas do conhecimento. Já a segunda envolve a articulação das áreas do conhecimento a partir de experiências e vivências (RIO GRANDE DO SUL, 2011-2014). Ambos estão expressos na Figura 4. 
Quadro 4 - Excertos D

A articulação dos dois blocos do currículo, por meio de projetos construídos nos seminários integrados, se dará pela interlocução, nos dois sentidos, entre as áreas de conhecimento e os eixos transversais, oportunizando apropriação e possibilidades do mundo do trabalho.

Os Seminários Integrados constituem-se em espaços planejados, integrados por professores e alunos, a serem realizados desde o primeiro ano e em complexidade crescente.

A realização dos seminários integrados constará na carga horária da parte diversificada, proporcionalmente distribuída do primeiro ao terceiro ano, constituindo-se em espaços de comunicação, socialização, planejamento e avaliação das vivências e práticas do curso.

Fonte: Rio Grande do Sul (2011-2014, p. 23).

À organização curricular, foi adicionada mais uma disciplina, o "SI", responsável pelo surgimento de várias discussões, tais como as da Figura 5:

\section{Quadro 5 - Excertos E}

[...] o governo reduz o conhecimento repassado aos alunos devido aos seminários integrados. A carga horária necessária para o desenvolvimento dos projetos interfere no andamento das aulas curriculares.

[...] a carga horária dos seminários poderia ser melhor aproveitada para trabalhar mais as disciplinas.

Fonte: A Hora (22 ago. 2013, p. 4).

Já o documento Regimento Referência afirma que a pesquisa na disciplina de "SI" é estruturada e praticada por intermédio do Projeto Vivencial:

Quadro 6 - Excertos F

Pesquisa pedagogicamente estruturada e praticada através de Projeto Vivencial- possibilita a construção de novos conhecimentos e a formação de sujeitos pesquisadores, críticos e reflexivos no cotidiano da escola, [...]. Esse Projeto Vivencial será elaborado, com a mediação do educador, no Seminário Integrado, em interlocução com as áreas do conhecimento e os eixos transversais.

Fonte: Rio Grande do SUL (2012, p. 15).

Demais estudos, como os de Ferreira (2013), apontam que o "SI" tem como propósito uma interlocução entre ciência, tecnologia, cultura e trabalho. A autora, em suas reflexões, realiza um aprofundamento do referencial metodológico, como o do "SI". Para ela, essa disciplina, ao ser trabalhada de forma interdisciplinar, “[...] utiliza a pesquisa científica como estratégia metodológica, propicia a construção do conhecimento social e historicamente situado, articulado com a vida produtiva” (FERREIRA, 2013, p. 189). Além disso, ao abordar o "SI", enfatiza as contribuições da LDB para o desenvolvimento da formação integral por 
meio "[...] da capacidade de pesquisar, buscar, organizar, selecionar e analisar informações para a aplicação do conhecimento" (FERREIRA, 2013, p. 189).

A “pesquisa" e o "SI" são compreendidos também por Azevedo e Reis (2013) de forma interligada. Para os autores, "A pesquisa no SI tem uma centralidade essencial para a construção do conhecimento conectado com o mundo do trabalho" (AZEVEDO; REIS, 2013, p. 36).

O Parecer no 5/2011 (p. 22) e as Diretrizes Curriculares Nacionais (2013, p. 163-164) também compreendem a adoção da "pesquisa como princípio pedagógico". Ademais, ambos vislumbram a prática da pesquisa para o desenvolvimento da atitude científica, ou seja, trabalhar com a pesquisa significa "[...] desenvolver a capacidade de aprender, de pesquisar e de buscar e (re) construir conhecimentos" (BRASIL, 2011, p. 41. BRASIL, 2013, p. 164). Em 1988, a Constituição Federal, no Art. 206, inciso II, e no Art. 208, inciso V, e, em 1996, a LDB, nos artigos $1^{\circ}, 3^{\circ}$ e $4^{\circ}$, também proferem a necessidade de aliar o "ensino à pesquisa".

O documento da Proposta Pedagógica 2011-2014, amparado na Legislação vigente, alia a pesquisa ao protagonismo, pois, a partir dela, acontece a formação de "[...] novos conhecimentos e de sujeitos pesquisadores, críticos e reflexivos" (RIO GRANDE DO SUL, 2011-2014, p.20). Nessa ótica, ela é considerada um “princípio pedagógico” (RIO GRANDE DO SUL, 2011-2014, p.21), pois

\section{Quadro 7 - Excertos G}

[...] propicia o desenvolvimento da atitude científica, o que significa contribuir, entre outros aspectos, para o desenvolvimento de condições de, ao longo da vida, interpretar, analisar, criticar, refletir, rejeitar ideias fechadas, aprender, buscar soluções e propor alternativas, potencializadas pela investigação e pela responsabilidade ética assumida diante das questões políticas, sociais, culturais e econômicas.

Fonte: UNESCO apud Rio Grande do SUL (2011-2014, p. 21).

\section{Quadro 8 - Excertos H}

Como forma de produzir conhecimento e como crítica da realidade, a pesquisa apoiar-se-á nas áreas de conhecimento ou nas disciplinas escolares para o desenho da metodologia e dos instrumentos de investigação, para a identificação das variáveis de estudo e para a interpretação dos resultados.

Fonte: Brasil, Protótipos Curriculares de Ensino Médio e Ensino Integrado (2011, p. 9).

De acordo com esse documento, a pesquisa escolar é uma forma de produção de conhecimento ancorada pelas distintas áreas do conhecimento. Caberia ao professor orientar 
e motivar seus alunos para que buscassem e construíssem seus próprios conhecimentos.

Nessa ótica, entendemos que a arqueologia foucaultiana dos discursos é uma interrogação sobre as condições de emergência de campos discursivos que sustentam práticas ou as engendram. Por conta desse entendimento, os enunciados dos professores, da mídia, dos documentos em torno da pesquisa escolar não possuem existência latente, pois se referem ao dito ou escrito em sua dispersão de acontecimentos. Ou seja, o que interessa nesse referencial teórico é como determinados enunciados tenham existido e outros não, bem como a intenção do sujeito falante. Dessa forma, os enunciados deste estudo mostram suas correlações e exclusões, pois, para a arqueologia, o que interessa é como determinados enunciados tenham existido e não outros, a intenção do sujeito falante, ou seja, não importa saber qual é a instância fundadora dos enunciados.

A partir do até aqui exposto, na última seção deste texto, apresentamos algumas considerações finais advindas dos resultados da investigação.

Inicialmente, destacamos que, de acordo com o referencial teórico escolhido para sustentar a investigação, não é nosso intuito emitir opiniões acerca da Proposta do Ensino Médio Politécnico, tampouco sobre a ação dos docentes nela envolvidos. A Proposta da Secretaria de Educação/RS para as Escolas Estaduais do Rio Grande do Sul apresentou a pesquisa escolar como princípio pedagógico que resolveria os problemas do Ensino Médio. De fato, os documentos estudados neste trabalho expressam a necessidade da incorporação da pesquisa na prática pedagógica dos professores das Escolas Estaduais de Ensino Médio do Rio Grande do Sul.

Em relação ao que apresentavam os documentos relativos ao Ensino Médio, a pesquisa deveria ser desenvolvida pelos docentes da disciplina de Seminário Integrado e também enquanto princípio pedagógico, articulando as áreas do conhecimento. Já este estudo fez com que entendêssemos como foram emergindo os discursos em torno dos documentos base do Ensino Médio Politécnico nesse momento histórico, do porquê dessa Proposta e não outra e, em especial, problematizássemos a pesquisa escolar como princípio pedagógico.

Cabe, assim, questionar como esse discurso foi se constituindo como a solução para os problemas observados nos processos de ensino e de aprendizagem no Ensino Médio. O fato é que os enunciados mostram que a pesquisa na prática do Ensino Médio Politécnico nem sempre era compreendida e operacionalizada dessa forma. Segundo alguns professores, 
desenvolvia-se, principalmente, na disciplina de Seminário Integrado. Para outros, essa compreensão necessitava ir além da disciplina e ser vista como uma Proposta de Ensino Médio.

Os enunciados dos docentes, durante a técnica de grupo focal, comprovam que ela acontecia apenas na disciplina de Seminário Integrado e não como princípio pedagógico disposto na Legislação para o Ensino Médio e, consequentemente, descrito na Proposta do Politécnico. Portanto, o ensino pela pesquisa se constitui enquanto princípio pedagógico por meio de uma política pública implementada em todas as escolas gaúchas.

Mesmo não tendo a pretensão de emitir verdades ou soluções "mágicas" para os problemas do Ensino Médio, os resultados da investigação nos levaram a pensar que a pesquisa, até há pouco tempo, era exclusivamente desenvolvida por pesquisadores universitários com uma longa caminhada acadêmica, ou seja, muito pouco refletida no interior da instituição escolar de nível básico. A questão é se existe a possibilidade de o docente da Escola Básica enveredar por esse caminho e estaria ele "capacitado" para tal. Corazza (2013), ao expressar que todo o professor é um pesquisador, problematiza que, se não for assim, como e o que ele ensinaria? Nesse contexto, destacamos que o como "fazer pesquisa" foi sendo constituído entre os professores por meio de um conjunto de formulações realizadas ao longo da história da educação.

Dessa forma, o desafio do educador em tempos emergentes está na criação e na inovação de uma pesquisa-docência que provoque rupturas nas formas de ensinar e de aprender. Para vencê-lo, é imprescindível que os professores desse nível de ensino ocupem espaços de estudos e de investigação dentro das instituições escolares. Ou seja, que (re) inventem os ambientes escolares e os transformem em espaços de potência de produção e criação de conhecimento por meio da pesquisa. Esta não precisa estar atrelada a uma disciplina criada e incluída em um currículo por uma determinada Secretaria de Educação. Enquanto potência, ela, de fato, deve permear e fazer parte da formação dos docentes, constituindo-os como professores-pesquisadores e, consequentemente, levar os alunos a serem pesquisadores. 


\section{Referências}

AHORA. Politécnico mostra dilema em novo modelo de ensino. Lajeado, 22 ago. 2013.

AZEVEDO, José Clovis de; Reis, Jonas Tarcísio. Democratização do ensino médio: a reestruturação curricular no RS. In: Azevedo, José Clovis de; Reis, Jonas Tarcísio.

Reestruturação do ensino médio: pressupostos teóricos e desafios da prática. 1. ed. São Paulo: Fundação Santillana, 2013. p. 25-48.

BRASIL. Constituição da República Federativa do Brasil. Brasília, 1988. Disponível em: http://www.planalto.gov.br/ccivil_03/Constituicao/Constituicao.htm\#adct. Acesso em: 29 abr. 2014.

BRASIL. Ministério da Educação. Diretrizes Curriculares Nacionais Gerais da Educação Básica. Secretaria de Educação Básica. Brasília: MEC, SEB, DICEI, 2013. Disponível em: http://educacaointegral.org.br/wpcontent/uploads/2014/07/diretrizes_curiculares_nacionais_2 013. Acesso em: 24 nov. 2013.

BRASIL. Ministério da Educação. Lei $n^{\circ} 9.394$ de 20 de dezembro de 1996. Estabelece as diretrizes e bases da Educação Nacional. Brasília, 1996. Disponível em:

http://www.planalto.gov.br/ccivil_03/leis/19394.htm. Acesso em: 24 nov. 2013.

BRASIL. Ministério da Educação. Protótipos curriculares de Ensino Médio e Ensino Médio integrado. UNESCO 2011. Coordenação: Setor de Educação da Representação da UNESCO no Brasil. Brasília: Debates Ed. n. 1, maio 2011.

BRASIL. Ministério da Educação. Secretaria de Educação Básica. Parecer $C N B / C E B n^{o}$ 5/2011. Diretrizes Curriculares Nacionais para o Ensino Médio. Brasília, 2011. Disponível em: http://pactoensinomedio.mec.gov.br/images/pdf/pceb005_11.pdf. Acesso em: $10 \mathrm{dez}$. 2013.

CORAZZA, Sandra Mara. Pesquisar o acontecimento estudo em XII exemplos. In: CORAZZA, Sandra Mara; SILVA, Tomaz Tadeu da; ZORDAN, Paola. Linhas de escrita. Belo Horizonte: Autêntica, 2004. p. 7-78.

CORAZZA, Sandra Mara. O que se transcria em educação? Porto Alegre, RS: UFRGS; Doisa, 2013.

COSTA, Marisa Vorraber. Velhos temas, novos problemas - a arte de perguntar em tempos pós-modernos. In: COSTA, Marisa Vorraber; BUJES, Maria Isabel Edelweiss (orgs.). Caminhos Investigativos III: riscos e possibilidades de pesquisar nas fronteiras. Rio de Janeiro: DP\&A, 2005. p. 199-214.

DAL'IGNA, Maria Cláudia. Grupo focal na pesquisa em educação: passo a passo teóricometodológico. In: MEYER, Dagma Estermann; PARAÍSO, Marlucy Alves. Metodologias de Pesquisas Pós-críticas em Educação. Belo Horizonte: Mazza Edições, 2012. p. 195-217.

FERREIRA, Vera Maria. Ensino Médio Politécnico: mudança de paradigmas. In: AZEVEDO, José Clovis de. REIS, Jonas Tarcísio. Reestruturação do Ensino Médio: 
Pressupostos teóricos e desafios da prática. 1. ed. São Paulo: Fundação Santillana, 2013. p. 187-206.

FOUCAULT, Michel. A arqueologia do saber. 7. ed. Rio de Janeiro: Editora Forense Universitária, 2008.

FOUCAULT, Michel. A ordem do discurso. Aula inaugural do Collège de France, pronunciada em 2 de dezembro de 1970. 22. ed. Tradução de Laura Fraga de Almeida Sampaio. São Paulo: Edições Loyola, 2012.

KOHAN, Walter Omar. Sócrates e Foucault professores: Entre o Ensino do já sabido e a busca por ensinar diferentemente. In: GALLO, Sílvio. SOUZA, Regina Maria de. Educação do preconceito Ensaios sobre poder e resistência. Campinas: Editora Alínea, 2004. p. 117130.

O INFORMATIVO. Alunos renegam Ensino Politécnico. Lajeado, 20 ago. 2013.

O INFORMATIVO. Ensino Médio Politécnico: ainda é cedo para avaliar? Lajeado, 06 abr. 2013.

OHLWEILER, Mariane Inês. A pesquisa como prática curricular ou o currículo como prática investigativa. In: MUNHOZ, Angélica Vier et al. Diálogos na contemporaneidade.

Coletâneas. Currículo. Lajeado: Univates, v. 1, 2012. p. 73-90.

RIO GRANDE DO SUL. Regimento Referência das escolas de Ensino Médio Politécnico da Rede Estadual. Secretaria da Educação. Porto Alegre, 2012.

RIO GRANDE DO SUL. Secretaria da Educação. Governo do Estado. Proposta Pedagógica para o Ensino Médio Politécnico e Educação Profissional Integrada ao Ensino Médio. Porto Alegre, 2011-2014.

SILVA, Monica Ribeiro da. Juventudes e Ensino Médio: possibilidades diante das novas DCN. In: AZEVEDO, José Clovis de. REIS, Jonas Tarcísio. Reestruturação do Ensino Médio: pressupostos teóricos e desafios da prática. 1. ed. São Paulo: Fundação Santillana, 2013. p. $65-80$. 